BMJ Open

Diabetes

Research

\& Care

\section{Lifetime risk and years lost to type 1 and type 2 diabetes in Denmark, 1996- 2016}

To cite: Carstensen B, Rønn PF, Jørgensen ME. Lifetime risk and years lost to type 1 and type 2 diabetes in Denmark, 1996-2016. BMJ Open Diab Res Care 2021;9:e001065. doi:10.1136/ bmjdrc-2019-001065

- Supplemental material is published online only. To view, please visit the journal online (http://dx.doi.org/10.1136/ bmjdrc-2019-001065).

Received 20 November 2019 Revised 2 November 2020 Accepted 20 January 2021
Check for updates

(c) Author(s) (or their employer(s)) 2021. Re-use permitted under CC BY-NC. No commercial re-use. See rights and permissions. Published by BMJ.

${ }^{1}$ Steno Diabetes Center Copenhagen, Gentofte, Denmark

${ }^{2}$ Clinical Epidemiology, University of Southern Denmark, National Institute of Public Health, Copenhagen, Denmark

Correspondence to Dr Marit Eika Jørgensen; marit.eika.joergensen@ regionh.dk

\section{ABSTRACT}

Introduction Lifetime risk and lifetime lost to diabetes are measures of current diabetes burden in a population. We aimed at quantifying these measures in the Danish population.

Research design and methods We modeled incidence and mortality of type 1 diabetes (T1D) and type 2 diabetes (T2D) and non-diabetes mortality based on complete follow-up of the entire population of Denmark in 19962016. A multistate model with these transition rates was used to assess the lifetime risk of diabetes, as well as the difference in expected lifetime between persons with type 1 and T2D and persons without.

Results In 2016, the lifetime risk of T1D was $1.1 \%$ and that for T2D 24\%, the latter a 50\% increase from 1996. For 50 -year-old persons, the lifetime lost was 6.6 years for T1D and 4.8 years for T2D. These figures have been declining over the study period.

At 2016, the total foreseeable lives lost in Denmark among patients with T1D were 182000 years, and those among patients with T2D were 766000 years, corresponding to 6.6 and 3.0 years per person, respectively.

Conclusion At the individual level, improvements in the disease burden for both T1D and T2D have occurred. At the population level, the increasing number of patients with T2D has contributed to a large increase in the total loss of lifetime.

\section{INTRODUCTION}

Relatively few studies have looked at lifetime lost to diabetes, ${ }^{1-5}$ and even fewer have provided figures of the lifetime risk of diabetes. ${ }^{1267}$ The lifetime lost or years of life lost to a disease have been given many interpretations in the literature (for an overview, see Andersen ${ }^{8}$ ). In this study, we used the standard definition from demography, namely, as the difference in expected lifetime between persons with and without diabetes at a given age. We base our calculations of lifetime risk and of lifetime lost to diabetes on a proper multistate model, taking both type 1 diabetes (T1D) and type 2 diabetes (T2D) into account.

\section{RESEARCH DESIGN AND MATERIAL \\ Data}

We used a newly established Danish Diabetes Register $^{9} 10$ linked to the total population

\section{Significance of this study}

What is already known about this subject?

- Studies from the Western world have shown that the years of life lost to diabetes in mid-life (around 50 years) is between 5 and 10 years, with large difference between countries.

- Studies have focused on either type 1 diabetes (T1D) or type 2 diabetes (T2D) or have not distinguished between types of diabetes.

What are the new findings?

- In similar ages, the years of life lost to T1D are about twice as high as for T1D; for 50-year-old persons the lifetime lost was 6.6 years for T1D and 4.8 years for T2D. This has been decreasing over the last decades.

- The lifetime risk of $\mathrm{T} 1 \mathrm{D}$ is currently $1.1 \%$, and that for for T2D is $24 \%$. At 2016, the total foreseeable life lost in Denmark among patients with T1D was 182000 years, and that among patients with T2D was 766000 years.

How might these results change the focus of research or clinical practice?

- There is a clear indication that the individual outlook for a person with diabetes is improving, whereas the population burden is increasing, indicating the prevention is an important focus area.

of Denmark, including the causes of death register. Detailed information on diabetes incidence, prevalence, mortality, and current and predicted future numbers with diabetes is given in previous publications. ${ }^{9} 10 \mathrm{We}$ constructed tables of person-years, incident cases of T1D, T2D and deaths by cause for the entire Danish population subdivided by current diabetes status (no diabetes, T1D and T2D). The causes of death used were cardiovascular disease (International Statistical Classification of Diseases and Related Health Problems, 10th Revision (ICD-10): I00-I999), cancer (ICD-10: C00-D099, so carcinoma in situ are included, benign and unspecified tumors excluded), respiratory (ICD-10: J00J999) and other causes. These tables were classified by sex, age and date of follow-up and 


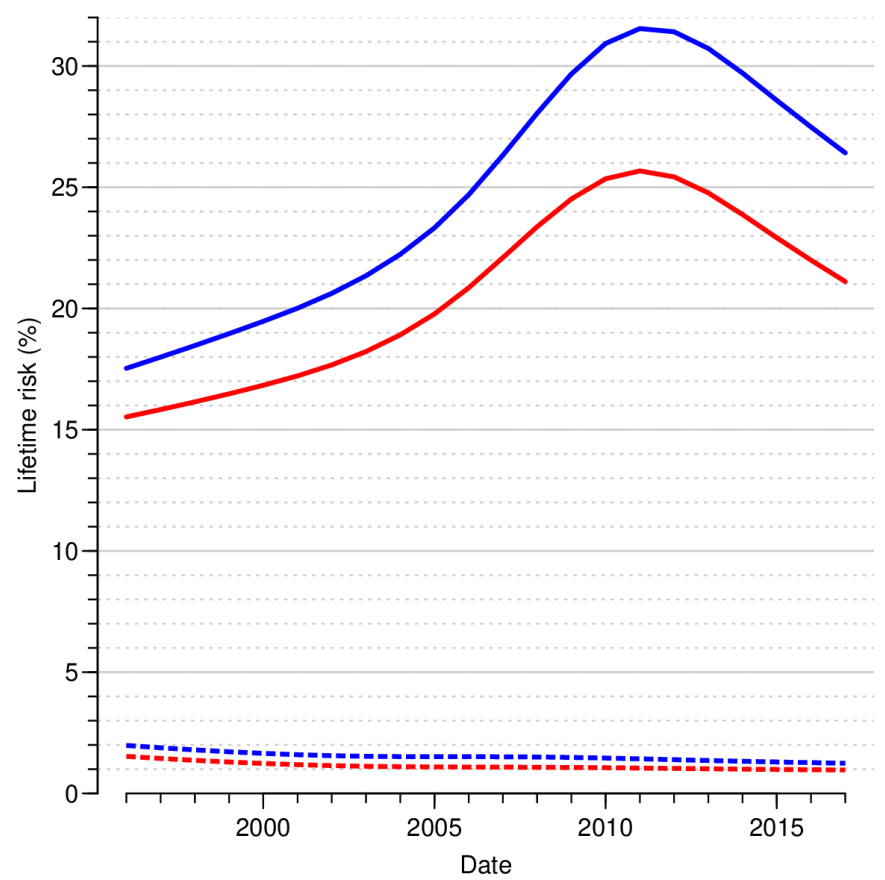

Figure 1 Lifetime risk of T1D and T2D by sex and date of reference. The calculations are based on annual estimated cross-sectional incidence and mortality rates from ageperiod-cohort models for incidence and mortality. Blue curves are men, red curves women; dotted lines T1D, full lines T2D. T1D, type 1 diabetes; T2D, type 2 diabetes.

date of birth in 1-year intervals, so called Lexis triangles ${ }^{11}$; further details are given in the electronic online supplemental material 1 (ESM), including a detailed overview of causes of death (online supplemental table 2)

\section{Statistical methods}

We fitted models for incidence rates of T1D and T2D, and cause-specific mortality rates for persons without diabetes and with T1D and T2D separately. All models were ageperiod-cohort (APC) models with smooth effects of current age, date of follow-up (period) and date of birth (cohort), providing estimated age-specific rates at each January 1, 1996-2017. Analyses were done separately for men and women-for further details, see the ESM.

Estimated rates were used in a multistate model with states 'no diabetes', 'T1D', 'T2D' and the four causes of death.

\section{Measures}

The lifetime risk of diabetes is the probability of getting diabetes before death. The expected lifetime (at birth) is the area under the survival curve, so the lifetime lost to diabetes is the difference in the area between the survival curves for a person with and a person without diabetes. If we condition on being alive at a given age, we used the conditional survival curves for that age. We subdivided the years of life lost by cause of death. ${ }^{8}$

We used the age-specific rates at each January 1 to compute the lifetime risk of T1D and T2D and the years of life lost to different causes of death. We also computed the population burden as the future years of life lost, both among prevalent cases of diabetes at a given date and among persons diagnosed with diabetes during a given year. A detailed account of methods used for computation of these measures is in the ESM.

\section{RESULTS}

In the study period 1996-2016 inclusive, there were 19712 T1D diagnoses and 343952 T2D diagnoses, while there was 12762 deaths among patients with T1D, 149000 among patients with T2D and 988569 among persons without diabetes (online supplemental table 1). The dominant single cause of death was CVD except for T1D, where the dominant cause of death was other causes.

\section{Lifetime risk of diabetes}

The lifetime risk of T1D declined from $2.0 \%$ to $1.2 \%$ for men and from $1.5 \%$ to $1.0 \%$ for women over the study period, while lifetime risk for T2D showed a peak around 2011 of more than $30 \%$ for men and $25 \%$ for women (driven by the very high recorded incidences that year ${ }^{9}$ ). The lifetime risk of T2D was $26 \%$ for men and $21 \%$ for women on January 1, 2017, corresponding to increases of $51 \%$ and $36 \%$ since 1996 (figure 1 and table 1).

\section{EXPECTED LIFETIME}

In the study period, the expected lifetime (at birth) without diabetes increased from 70.2 to 74.4 for men and from 75.5 to 78.8 years for women. At the population level, the expected lifetime spent (sojourn time) with T1D was 0.6 years for men and 0.5 years for women, unchanged over the study period, while the expected lifetime with T2D increased from 2.0 to 4.6 years, similar for men and women (table 1). Thus, of the increase in expected lifetime in the period, more than half was expected to be years with T2D (table 1).

\section{Years of life lost to diabetes}

At the beginning of 2017, the lifetime lost to T1D was 8.3 years at age 20 years and about 5.6 years at age 60 years (online supplemental table 5). Lifetime lost to T2D at age 60 years was 3.8 years (online supplemental table 6 ), so T1D carries about $30 \%$ higher lifetime loss compared with T2D (figure 2 and online supplemental tables 5 and 6), reflecting the earlier diagnosis and hence longer duration of diabetes at a given age for T1D as compared with T2D. We also found that the years lost to diabetes have been diminishing over the study period, at age 50 years from about 9 to 7 years for T1D and from 8 to 5 years for T2D.

\section{Future years of life lost}

The future years of life lost among patients with prevalent diabetes - the currently accumulated future population burden in Denmark-was 947600 years on January 1, 2017 (online supplemental table 3), 19\% of which were among persons with T1D, despite only $10 \%$ of Danish 
Table 1 Lifetime risk, expected lifetime spent with diabetes and lifetime lost by type of diabetes, sex and date (January 1 each year)

\begin{tabular}{|c|c|c|c|c|c|c|c|c|c|c|c|c|c|}
\hline \multirow[b]{3}{*}{ Date } & \multirow{2}{*}{\multicolumn{2}{|c|}{$\begin{array}{l}\text { Lifetime risk } \\
(\%)\end{array}$}} & \multirow{2}{*}{\multicolumn{3}{|c|}{$\begin{array}{l}\text { Expected lifetime (years) } \\
\text { spent with }\end{array}$}} & \multicolumn{8}{|c|}{ Lifetime lost (years) to } \\
\hline & & & & & & \multicolumn{4}{|c|}{ T1D, at ages } & \multicolumn{4}{|c|}{ T2D, at ages } \\
\hline & T1D & T2D & No DM & T1D & T2D & 25 & 40 & 50 & 60 & 40 & 50 & 60 & 75 \\
\hline \multicolumn{14}{|l|}{ Men } \\
\hline 1996 & 2.0 & 17.5 & 70.2 & 0.6 & 2.1 & 9.6 & 8.3 & 6.6 & 4.7 & 9.5 & 7.7 & 5.7 & 2.9 \\
\hline 1999 & 1.7 & 19.0 & 70.9 & 0.5 & 2.4 & 11.4 & 10.0 & 8.2 & 6.1 & 8.7 & 7.1 & 5.2 & 2.7 \\
\hline 2002 & 1.6 & 20.6 & 71.5 & 0.5 & 2.8 & 12.7 & 11.1 & 9.3 & 6.9 & 8.1 & 6.5 & 4.9 & 2.4 \\
\hline 2005 & 1.5 & 23.3 & 71.8 & 0.5 & 3.4 & 13.2 & 11.6 & 9.7 & 7.3 & 7.3 & 5.9 & 4.4 & 2.2 \\
\hline 2008 & 1.5 & 28.1 & 71.4 & 0.5 & 4.4 & 13.6 & 12.0 & 10.1 & 7.8 & 6.4 & 5.1 & 3.9 & 2.0 \\
\hline 2011 & 1.4 & 31.5 & 71.4 & 0.6 & 5.2 & 12.4 & 11.0 & 9.4 & 7.5 & 5.7 & 4.6 & 3.5 & 1.9 \\
\hline 2014 & 1.3 & 29.7 & 72.7 & 0.6 & 5.1 & 10.2 & 9.1 & 7.9 & 6.4 & 5.6 & 4.6 & 3.6 & 2.0 \\
\hline 2017 & 1.2 & 26.4 & 74.4 & 0.6 & 4.6 & 8.1 & 7.3 & 6.3 & 5.2 & 5.7 & 4.7 & 3.7 & 2.1 \\
\hline \multicolumn{14}{|l|}{ Women } \\
\hline 1996 & 1.5 & 15.5 & 75.5 & 0.5 & 2.0 & 10.9 & 9.7 & 8.3 & 6.4 & 9.5 & 8.1 & 6.3 & 3.5 \\
\hline 1999 & 1.3 & 16.5 & 75.9 & 0.4 & 2.3 & 11.5 & 10.3 & 9.1 & 7.1 & 8.6 & 7.3 & 5.7 & 3.2 \\
\hline 2002 & 1.1 & 17.7 & 76.3 & 0.4 & 2.6 & 11.9 & 10.8 & 9.5 & 7.7 & 7.8 & 6.6 & 5.1 & 2.9 \\
\hline 2005 & 1.1 & 19.8 & 76.5 & 0.4 & 3.2 & 12.4 & 11.2 & 9.9 & 8.1 & 7.0 & 5.9 & 4.6 & 2.5 \\
\hline 2008 & 1.1 & 23.4 & 76.2 & 0.4 & 4.0 & 12.6 & 11.4 & 10.2 & 8.4 & 6.2 & 5.2 & 4.0 & 2.1 \\
\hline 2011 & 1.0 & 25.7 & 76.3 & 0.5 & 4.7 & 11.4 & 10.4 & 9.4 & 7.9 & 5.7 & 4.8 & 3.7 & 2.0 \\
\hline 2014 & 1.0 & 23.9 & 77.4 & 0.5 & 4.5 & 9.8 & 9.0 & 8.1 & 6.9 & 5.6 & 4.8 & 3.7 & 2.0 \\
\hline 2017 & 1.0 & 21.1 & 78.8 & 0.5 & 4.1 & 8.2 & 7.6 & 6.9 & 6.0 & 5.7 & 4.9 & 3.8 & 2.1 \\
\hline
\end{tabular}

Note the different ages at calculation of life lost for T1D and T2D, accommodating the different age distributions of T1D and T2D. DM, diabetes mellitus; T1D, type 1 diabetes; T2D, type 2 diabetes.

patients with diabetes are T1D. ${ }^{9}$ The average future lifetime lost was 6.6 years for T1D and 3.0 years for T2D, partly attributable to different age distributions.

The extra future lifetime lost among newly diagnosed patients with diabetes in a single year was around 70000 years during 2016, some $10 \%$ of these from T1D, even if only $5 \%$ of newly diagnosed cases are T1D (online supplemental table 3). The average lifetime lost for persons diagnosed in 2016 were 8.2 years for T1D and 3.6 years for T2D (online supplemental figure 2 ).

For both of these measures, we found an increase at the population level over time, but at the individual level, we found that the average lifetime lost among patients was decreasing over the study period, over the last 10 years, some $35 \%$ for T1D, but less than $10 \%$ for T2D (online supplemental tables 3 and 4).

\section{Years of life lost by cause of death}

We found that the major contributor to years of life lost in T1D (online supplemental table 5 and online supplemental figures 4-7) was other causes of death (4.1 years at age 50) and only second was CVD (2 years at age 50), whereas respiratory causes contribute slightly less than 1 year throughout the age range. Cancer contributes almost nothing in women with T1D and a negative 1 year among men with T1D. In T2D (online supplemental table 6 and online supplemental figures 4-7), other causes and CVD contribute similar amounts of life lostabout 1.5 years each at age 50 , and respiratory causes less than 0.5 years.

\section{DISCUSSION}

Our study is the first to simultaneously evaluate the lifetime risk as well as the lifetime lost to T1D and T2D in an entire population using a proper multistate methodology. We evaluated both the individual and the population levels of years of life lost to diabetes.

We found the lifetime risk of T1D to be just over $1 \%$ and that of T2D to be about 25\% - both of these figures properly account for the competing type of diabetes as well as death, and the lifetime risk of any type of diabetes is therefore $26 \%$.

Whichever way the lifetime lost to diabetes is illustrated, there has been a very clear improvement over the last two decades at the individual patient level, but the overall population burden, particularly for T2D, has been massively increasing.

Life years lost to T1D are some $30 \%$ higher than those lost to T2D at any given age. That may be due to longer exposure to risk factors for acute and chronic microvascular and macrovascular complications to diabetes with earlier onset. Furthermore, the aggressive approach to manage cardiometabolic risk factors in T2D is less well 


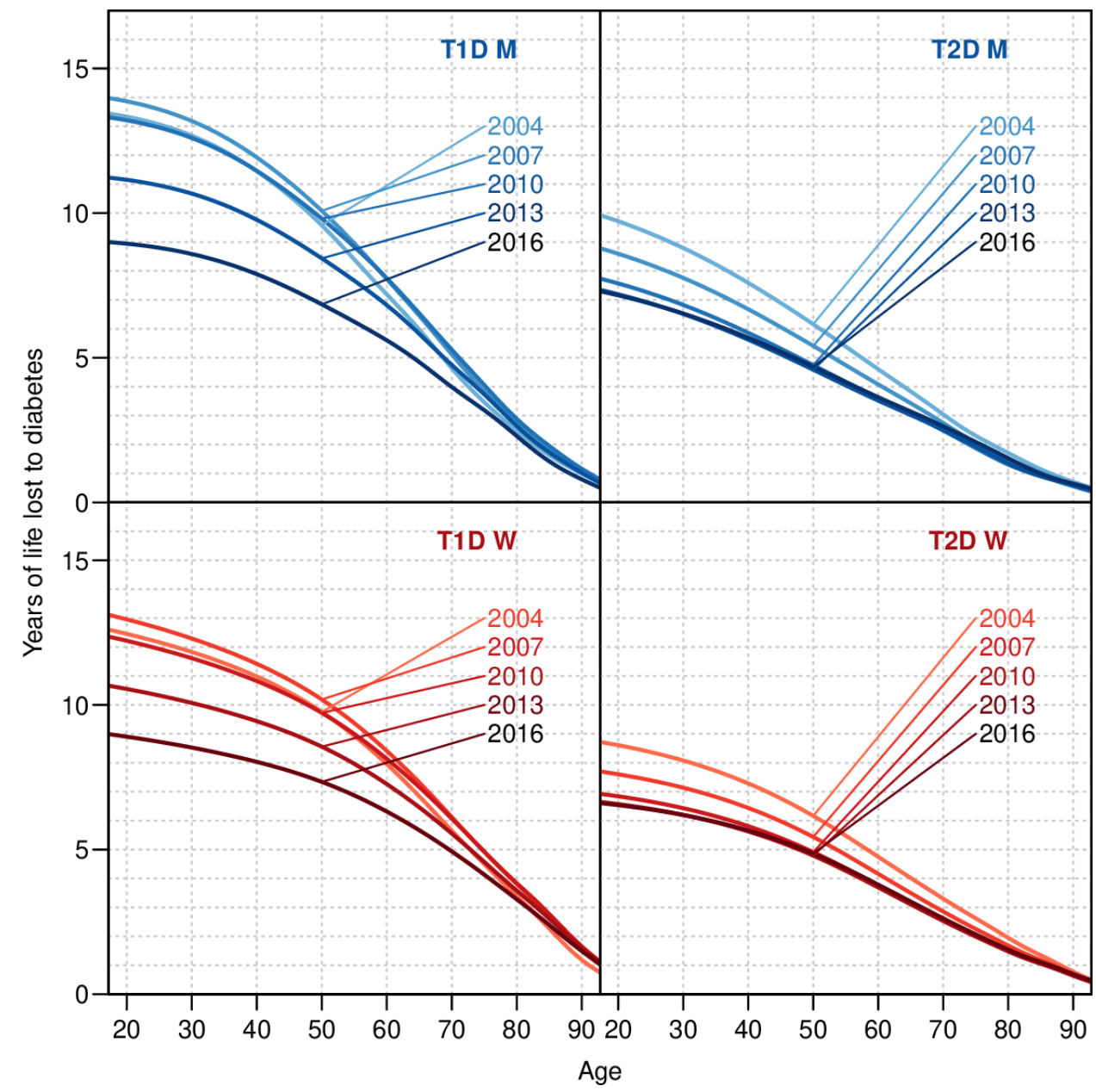

Figure 2 Years of life lost to T1D and T2D in January 1, 2004, 2007, .., 2016, by sex. The calculations are based on annual estimated cross-sectional incidence and mortality rates from age-period-cohort models for incidence and mortality. M, men; T1D, type 1 diabetes; T2D, type 2 diabetes; W, women.

documented in T1D, and quality registers have proven less favorable blood pressure and lipid levels in T1D compared with T2D, as well as some renal-protective and cardioprotective undertreatment. ${ }^{12}$

A number of studies modeling life years lost to diabetes $^{4513-16}$ are old or have used suboptimal methods for calculations or very crude model assumptions, and are therefore not directly comparable to ours. The studies by Narayan et $a l^{1}$ and Gregg et $a l^{2}$ use similar methodology as we do, comparing the mortality among persons with and without diabetes at a given survey date (ignoring subsequent diabetes development-not explicitly mentioned in any of the papers), which gives a more valid picture of the lifetime lost to diabetes. The most recent study by Gregg et al arrived at years of life lost to diabetes at age 40 years for white men of 5.8 and 6.8 years for white women in the period 2000-2011, where we found 7.3 and 7.0 years in 2005 . The validity of this study, however, is limited by the fact that the diagnosis of diabetes is derived from a telephone survey.

Livingstone $e t a \vec{b}$ provided estimates of lifetime lost to T1D in Scotland for the period 2008-2010 of 9.2 years for men and 10.8 years for women aged 40 years. Huo et $a l^{17}$ estimated the lifetime lost to T1D in Australia for the period 1997-2010 to 10.0 years for men and 11.2 years for women aged 40 years. For 2008, we found 6.4 years for men and 6.2 years for women at age 40 years somewhat smaller than the Scottish and Australian studies.

\section{Strengths and weaknesses}

A major strength of our study is the total population coverage, which eliminates sampling biases, and the use of a multistate model to compute realistic survival curves for persons without diabetes, taking the future possibility of both T1D and T2D into account. Moreover, we used 1-month updating intervals in model updating, minimizing the approximation bias, and we took calendar time and cohort trends in rates into account, enabling us to derive these measures for successive years, and thus realistically account for trends.

One study weakness is potential misclassification of insulin treated T2D as T1D in the early years of the diabetes register (before 2005). Thus, years of life lost to T1D may be underestimated before 2005 due to contamination with patients with T2D. 


\section{SUMIMARY}

Our study shows that there has been a decrease in lifetime risk of T1D to slightly over $1 \%$ and an increase in T2D risk to $25 \%$.

Further, we demonstrated a decline in the individual burden of T2D over the last two decades, but also clearly demonstrated that the population burden is increasing, indicating that preventive measures have not had the desired effect yet, and in particular, that the burden of T1D still is quite high, despite decreasing lifetime risk.

Acknowledgements We are grateful to the Danish Clinical Registries for providing access to the Danish Adult Diabetes Database and DiaBase for the construction of the diabetes register.

Contributors $\mathrm{BC}$ and MEJ conceived the structure of the underlying register. PFR provided support for obtaining data access and contributed to data definition. BC detailed and developed the study and the statistical methods needed, performed all data analysis, and wrote the first draft of the manuscript. MEJ and PFR contributed substantially to the writing of the manuscript. All authors contributed to critical revision and take responsibility for the content. BC is the guarantor of this work and, as such, had full access to all the data in the study and takes responsibility for the integrity of the data and the accuracy of the data analysis.

Funding The authors have not declared a specific grant for this research from any funding agency in the public, commercial or not-for-profit sectors.

Competing interests $\mathrm{BC}$ and MEJ own shares in NovoNordisk. $\mathrm{BC}$ has received lecture and consultancy fees from NovoNordisk and LeoPharma. MEJ is principal investigator on a trial sponsored by AstraZeneca and received research grants from AMGEN AB, AstraZeneca, Sanofi Aventis and Boehringer Ingelheim. PFR has nothing to disclose.

Patient consent for publication Not required.

Ethics approval This study was approved by the Danish Data Protection Agency (registration number 2015-41-4148). Ethical approval is not required for registerbased studies in Denmark.

Provenance and peer review Not commissioned; externally peer reviewed.

Data availability statement Data are not publicly available. The data for this study are population-wide registers, placed at our disposal on the servers of Statistics Denmark. They are barred from release to the public on grounds of confidentiality. A full documentation of the register is given in the electronic supplemental material.

Supplemental material This content has been supplied by the author(s). It has not been vetted by BMJ Publishing Group Limited (BMJ) and may not have been peer-reviewed. Any opinions or recommendations discussed are solely those of the author(s) and are not endorsed by BMJ. BMJ disclaims all liability and responsibility arising from any reliance placed on the content. Where the content includes any translated material, BMJ does not warrant the accuracy and reliability of the translations (including but not limited to local regulations, clinical guidelines, terminology, drug names and drug dosages), and is not responsible for any error and/or omissions arising from translation and adaptation or otherwise.

Open access This is an open access article distributed in accordance with the Creative Commons Attribution Non Commercial (CC BY-NC 4.0) license, which permits others to distribute, remix, adapt, build upon this work non-commercially, and license their derivative works on different terms, provided the original work is properly cited, appropriate credit is given, any changes made indicated, and the use is non-commercial. See: http://creativecommons.org/licenses/by-nc/4.0/.

ORCID iDs

Bendix Carstensen http://orcid.org/0000-0002-5161-2192

Marit Eika Jørgensen http://orcid.org/0000-0001-8356-5565

\section{REFERENCES}

1 Narayan KMV, Boyle JP, Thompson TJ, et al. Lifetime risk for diabetes mellitus in the United States. JAMA 2003;290:1884-90.

2 Gregg EW, Zhuo X, Cheng YJ, et al. Trends in lifetime risk and years of life lost due to diabetes in the USA, 1985-2011: a modelling study. Lancet Diabetes Endocrinol 2014;2:867-74.

3 Livingstone SJ, Levin D, Looker HC, et al. Estimated life expectancy in a Scottish cohort with type 1 diabetes, 2008-2010. JAMA 2015;313:37-44.

4 Leung M-YM, Pollack LM, Colditz GA, et al. Life years lost and lifetime health care expenditures associated with diabetes in the U.S., National health interview survey, 1997-2000. Diabetes Care 2015;38:460-8.

5 Wright AK, Kontopantelis E, Emsley R, et al. Life expectancy and cause-specific mortality in type 2 diabetes: a population-based cohort study quantifying relationships in ethnic subgroups. Diabetes Care 2017:40:338-45.

6 Carstensen B, Kristensen JK, Ottosen P, et al. The Danish national diabetes register: trends in incidence, prevalence and mortality. Diabetologia 2008;51:2187-96.

7 Carstensen B, Jørgensen ME, Friis S. The epidemiology of diabetes and cancer. Curr Diab Rep 2014;14:535.

8 Andersen PK. Decomposition of number of life years lost according to causes of death. Stat Med 2013;32:5278-85.

9 Carstensen B, Rønn PF, Jørgensen ME. Prevalence, incidence and mortality of type 1 and type 2 diabetes in Denmark 1996-2016. BMJ Open Diabetes Res Care 2020;8:e001071.

10 Carstensen B, Rønn PF, Jørgensen ME. Components of diabetes prevalence in Denmark 1996-2016 and future trends until 2030. BMJ Open Diabetes Res Care 2020;8:e001064.

11 Carstensen B. Age-Period-Cohort models for the Lexis diagram. Stat Med 2007;26:3018-45.

12 DiaBase DVDD, DanDiabKids. Dansk diabetes database, National arsrapport 2017/2018 (in Danish). technical report, 2019. Available: https://www.sundhed.dk/content/cms/87/4687_diabetes_2017_18_ offentliggoerelse_v2.pdf

13 Loukine L, Waters C, Choi BC, et al. Impact of diabetes mellitus on life expectancy and health-adjusted life expectancy in Canada. Popul Health Metr 2012;10:7.

14 Morgan CL, Currie CJ, Peters JR. Relationship between diabetes and mortality: a population study using record linkage. Diabetes Care 2000;23:1103-7.

15 Wang Z, Liu M. Life years lost associated with diabetes: an individually matched cohort study using the U.S. National health interview survey data. Diabetes Res Clin Pract 2016;118:69-76.

16 Norhammar A, Bodegård J, Nyström T, et al. Incidence, prevalence and mortality of type 2 diabetes requiring glucose-lowering treatment, and associated risks of cardiovascular complications: a nationwide study in Sweden, 2006-2013. Diabetologia 2016;59:1692-701.

17 Huo L, Harding JL, Peeters A, et al. Life expectancy of type 1 diabetic patients during 1997-2010: a national Australian registrybased cohort study. Diabetologia 2016;59:1177-85. 